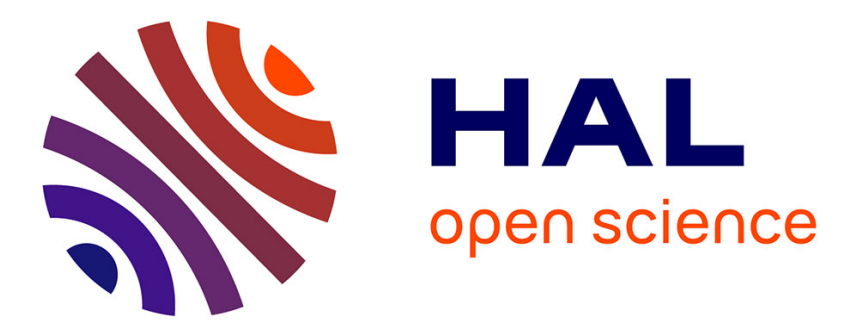

\title{
Measurement and modelling of high resolution flow-velocity data under simulated rainfall on a low-slope sandy soil
}

Lucile Tatard, Olivier Planchon, John Wainwright, Guillaume Nord, David Favis-Mortlock, Norbert Silvera, Olivier Ribolzi, Michel Esteves, Chi Hua Huang

\section{To cite this version:}

Lucile Tatard, Olivier Planchon, John Wainwright, Guillaume Nord, David Favis-Mortlock, et al.. Measurement and modelling of high resolution flow-velocity data under simulated rainfall on a lowslope sandy soil. Journal of Hydrology, 2008, 348 (1-2), pp.1-12. ird-00268400

\section{HAL Id: ird-00268400 \\ https://hal.ird.fr/ird-00268400}

Submitted on 1 Apr 2008

HAL is a multi-disciplinary open access archive for the deposit and dissemination of scientific research documents, whether they are published or not. The documents may come from teaching and research institutions in France or abroad, or from public or private research centers.
L'archive ouverte pluridisciplinaire HAL, est destinée au dépôt et à la diffusion de documents scientifiques de niveau recherche, publiés ou non, émanant des établissements d'enseignement et de recherche français ou étrangers, des laboratoires publics ou privés. 
1 Measurement and modelling of high resolution flow2 velocity data under simulated rainfall on a low-slope 3 sandy soil

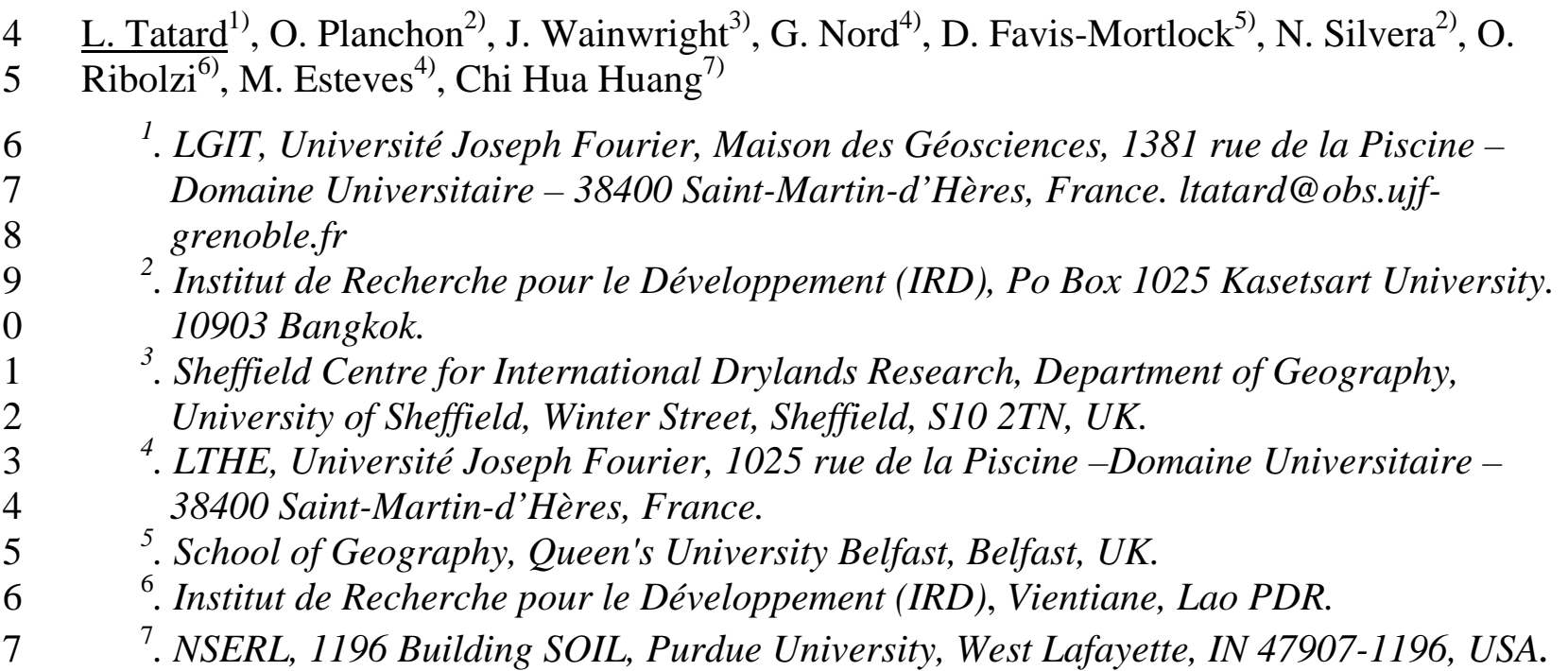

18

19

20

21

22

23

24

25

26

27

28

29

30

31

32

33

34

35

36

37

38

\begin{abstract}
The study presented here is focussed on the question of the hydraulic nature of the threshold that allows a rill to start. A rainfall-simulation experiment was carried out to produce highresolution flow-velocity data. The experiment employed a $10 \mathrm{~m} \times 4 \mathrm{~m}$ experimental plot with a $1 \%$ slope, which had been previously eroded and had a small rill formed in the middle. The experiment consisted of a $2 \mathrm{~h} \mathrm{15}$ '-long rainfall at a constant intensity of $69 \mathrm{~mm} \mathrm{~h}^{-1}$. Surface elevation was measured before rainfall at a horizontal resolution of $2.5 \mathrm{~cm}$ across, and $5 \mathrm{~cm}$ along the slope direction. During rainfall, flow velocities were measured at 68 locations on the plot with the Salt Velocity Gauge technology, an automated, miniaturized device based on the inverse modelling of the propagation of a salt plume. The experiment led to the collection of flow-velocity measurements which are novel in three ways: (i) the small size of the measured section, which was only $10-\mathrm{cm}$ long and $1-\mathrm{cm}$ wide, (ii) the wide range of measured flow velocities, which ranged from $0.006 \mathrm{~m} \mathrm{~s}^{-1}$ to $0.27 \mathrm{~m} \mathrm{~s}^{-1}$ and, (iii) the large number of measured locations.
\end{abstract}

The flow-velocity field was simulated with three models: PSEM_2D solves the Saint-Venant equations in 2D, MAHLERAN uses a 1D kinematic wave in the slope direction coupled with a 2D flow-routing algorithm, and Rillgrow2, which involves an empirical runoff algorithm that is close in principle to the diffusion-wave equation in 2D. The Darcy-Weisbach friction factor ( $f f$ ) and the infiltration parameters were calibrated in all cases to investigate the capabilities of the different models to reproduce flow hydraulics compatible with the onset of rilling. In a first 
set of numerical experiments, $f f$ was set uniform, and calibration used only the hydrograph. The comparison of simulated and observed flow-velocity field showed that PSEM_2D was the most satisfying model, at the cost of longer computational time. MAHLERAN gave surprisingly good results with regards to the simplicity of the model and its low computational needs. However, all models largely underestimated the highest velocity values, located in the rill. Furthermore, none of the models was able to simulate the Reynolds $(R e)$ and Froude $(F r)$ numbers. The next numerical experiment was done with PSEM_2D. Non-uniform ff values were calibrated by fitting the simulated flow-velocity field to the observed one. The latter simulation produced realistic simulations of $R e$ and Fr. The hydraulic conditions at the transition from interrill flow to rill flow are discussed. The results support the theory that supercritical flows are a necessary condition for a rill to emerge from a smooth surface.

Key words: rainfall simulation, water erosion, erosion models, rill, interrill, Senegal

\section{Introduction}

Rill erosion is a major contributor to sediment removal from agricultural fields. Recent studies based on rare earth elements have shown experimentally that rill erosion can produce 4.3 to 5 times (Song et al., 2003) and even 29 times (Whiting et al., 2001) as much sediment as interrill erosion. Even on small plots $(1.5 \times 3 \mathrm{~m})$, Yang et al. (2006) showed that simulated rainfall at an intensity of $73 \mathrm{~mm} \mathrm{~h}^{-1}$ can cause twice as much rill erosion as interrill erosion after only 13 min of runoff. The onset of rills, and the development of the rill pattern, can even be the key process that explains erosion on the most severe events. Cerdan et al. (2002), for example, reported $10 \mathrm{t} \mathrm{ha}^{-1}$ of rill and gully erosion in a single month in a 94-ha catchment in Normandy (France) during the dramatic winter of 1999, while water erosion in the region is normally dominated by interrill processes. However and despite these observations, the dynamics of rill patterns, and the onset of rilling, are not taken into account in most soil-erosion models, with the noticeable exception of experimental models, such as RillGrow (Favis-Mortlock, 1998) or novel models in their preliminary versions, such as PSEM_2D (Nord and Esteves, 2005) or MAHLERAN (Wainwright et al., in review). The WEPP model, described by Gilley et al. (1988), for example, assumes the rill density is one rill per metre transversally to the slope. In the LISEM model (de Roo et al., 1996) all erosion is assumed to be rill erosion, although rills are not explicitly simulated. During rainfall, such models are unable neither to modify the rill density nor to simulate its dynamics.

34

After they have developed in the landscape however, rill networks have been thoroughly described, and their density related to landscape properties (Patton and Schumm, 1975; Parsons 1987; Thorne and Zevenbergen, 1990; Montgomery and Dietrich, 1992; Vandaele et al., 1996; Desmet and Govers, 1997; Desmet et al., 1999). Experimental studies have been devoted to rill density, either in field such as in Mancilla et al. (2005) or laboratory experiments (Gómez et al., 2003; Rieke-Zap and Nearing, 2005; Darboux and Huang, 2005). Flow characteristics in rills have also received considerable attention (Govers, 1992; Abrahams et al., 1996; Nearing 
1 et al., 1997, Gimenez and Govers, 2001). It has even proved possible in some cases, like 2 Chaplot et al. (2005), to simulate rill development numerically during chosen storm events that 3 are already known to have caused rill erosion.

4 However, the dynamics of rilling is poorly known, since most field work, such as Desmet et al. 5 (1999) or Chaplot et al. (2005), refer to rill descriptions made after rainfall, with no 6 information about the onset and development of rills. As a consequence of the lack of information about the onset and development of rills, currently existing distributed erosion models are unable to predict whether rilling and gullying will occur or not during a given storm event. This is one of the acknowledged causes of their poor predictive capabilities reported by Jetten et al. (1999), whose conclusions are rewritten more abruptly in Jetten et al. (2003). A fundamental part of this problem is the ability of models to represent the processes at work in the landscape. At the transition from interrill flow to rill flow, these processes are critically represented by hydraulic properties of the flow. However, little attention has been paid in the literature to the ability of models to reproduce the specific hydraulic conditions at this transition.

The study presented here is therefore focussed on the question of the hydraulic nature of the threshold that allows a rill to start. A rainfall-simulation experiment was carried out to address this question. The experiment took place at Thies, Senegal, on a $40-\mathrm{m}^{2}$ plot with a sandy soil and low slope (1\%). Flow velocity was measured at 68 individual points on the plot with a miniaturized version of the salt velocity gauge (SVG) technology described by Planchon et al. (2005). SVG is an automated salt-tracing technique which provides reliable velocity data over a wide range of flow speeds and with no lower limit on flow depth. The apparatus specifically designed for this experiment allowed the flow velocity to be measured at a high resolution, averaging over $10-\mathrm{cm}$ long by 1 -cm wide sections of the flow.

Three existing models of different levels of complexity have been used, in order to test their ability to simulate the high resolution data made available by the SVG technology. The use of several models was expected to bring some insights about the research needs for the modelling of rill initiation and rill flow. At the same time, the study of the onset of rilling was expected to benefit from the variety of models used, especially if some common result was produced.

The question of the hydraulic nature of the threshold that allows a rill to start is directly related to the interactions between roughness and flow conditions. These interactions are potentially complex, especially in the presence of stones or vegetation, as reported by Abrahams et al. (1995). In such a case, the Darcy-Weisbach friction factor, ff, may increase or decrease with increasing Reynolds number, Re, depending of a number of other parameters such as flow depth and the nature of obstacles, as investigated experimentally by Järvelä (2002). In the absence of these complex conditions, the interaction between roughness and flow falls into two distinct categories.

First, laminar flows have decreasing values of $f f$ with increasing $R e$ in all cases, as reported by Dunkerley et al. (2001). Nearing et al. (1997) have also reported decreasing $f f$ with increasing $R e$ for $R e$ values up to 70,000 in a flume experiment carried on pure sorted quartz sand. The 
common characteristic to the two abovementioned experiments was the inability of the flow to significantly modify the soil roughness, either because of lack of available power in the laminar case, or because of specific precautions in the experimental design in the experiment of Nearing et al. (1997).

Secondly, in turbulent conditions, when strong feedback interactions allow the flow conditions to modify the bed roughness, $f f$ is found to increase with increasing $R e$ (Nearing et al., 1997; Hessel et al., 2003). Such feedback interactions were first described by Govers (1992), who showed that flow velocity in eroding rills is independent of the slope angle. This situation forms the second kind of interactions mentioned above, which involves the Froude number Fr. Grant (1997) hypothesized that in flows with mobile beds, $\mathrm{Fr}$ could not be higher than unity over long distances or long periods of time. Gimenez et al. (2004) investigated experimentally the reasons for such a limitation. They produced the following hypotheses: (i) critical flow was a necessary condition for rill initiation, and (ii) interaction with $F r$ is related to the development of small hydraulic jumps along the rill. In the light of the experiment of Gimenez et al. (2004), the role of Fr in the feedback between flow conditions and bed roughness can be explained as follows: when the flow is accelerating in a rill due to gravity, it finally reaches supercritical velocity. At supercritical velocities, any tiny change in the channel geometry (which obviously are many in a natural channel) will potentially generate a small hydraulic jump. The jump has two connected consequences: (1) by definition, the jump changes the flow conditions from supercritical to subcritical, thus preventing any eroding rill to sustain supercritical speed over long distances, and (2) the high turbulence associated with the jump results in eroding the channel at the jump location, thus enlarging the tiny irregularity that initially caused the jump. If this scenario is correct, supercritical velocity should be a necessary condition for a rill to emerge from a smooth surface. Investigating this hypothesis derived from the work of Gimenez et al. (2004) was thus a further objective of this experiment.

\section{Material and methods}

\section{The new generation of SVG}

30 The SVG technology has been presented in Planchon et al. (2005). It consists of injecting salty brine into the flow and recording the conductivity peak simultaneously at two locations downstream separated by a known distance of a few centimeters. The flow velocity is calculated by inverse modelling of the propagation of the conductivity peak between the two probes. The model used is a 1D convection-dispersion model (Eq. 1). Hayami (1951) cited by Henderson (1966), gave Eq. 2 as the solution of Eq. 1 when $\mathrm{C}(0, \mathrm{t})$ is the Dirac function, i.e. injection is instantaneous. Eq. 3 describes the least-squares sum that is minimized in the model used by the SVG.

$$
\frac{\partial C}{\partial t}=-u \frac{\partial C}{\partial x}+D \frac{\partial^{2} C}{\partial x^{2}}
$$




$$
C=\frac{x}{2 \sqrt{\pi \cdot D \cdot t^{3}}} \exp \left(-\frac{(u \cdot t-x)^{2}}{4 D \cdot t}\right)
$$

2 Where $C$ is salt concentration $\left(\mathrm{g}^{-1}\right) ; t$ is time (s); $x$ is the distance to the injection point (m); $u$ 3 is flow velocity $\left(\mathrm{m} \mathrm{s}^{-1}\right) ; D$ is dispersion $\left(\mathrm{m}^{2} \mathrm{~s}^{-1}\right)$.

4

$$
s s q=\sum_{t}\left[\left(C_{1} \otimes \bar{C}\right)-\left(a \cdot C_{2}+b\right)\right]^{2}
$$

5 Where $C_{1}$ and $C_{2}$ are salt concentration $\left(\mathrm{g} \mathrm{l}^{-1}\right)$ at the upstream and the downstream probe,

6 respectively; $\otimes$ is the convolution product; $\bar{C}$ is Hayami's solution from Eq. 2 with $x$ being the 7 inter-probe distance, i.e. $0.1 \mathrm{~m} ; a$ and $b$ are coefficients that account for salt losses between the

8 two probes (due to infiltration, lateral dispersion of the brine or other causes); ssq is the

9 quadratic sum that is minimized by fitting $\mathrm{u}, D, a$ and $b$ for each pair of peaks.

10 The new generation of SVG was operated by two persons. Operator A worked on a bench that crossed the plot, providing access to the centre of the plot during rainfall without stepping in it. S/he placed the probes at the measuring locations and injected salty brine a few centimetres upstream from the probes. The brine was coloured with potassium permanganate to allow for visual control of the tracing process. Four probes were multiplexed to the datalogger, allowing four locations to be measured simultaneously. Operator B was at the computer. After operator A had placed the probes, the data acquisition and the brine injection was simultaneously triggered at a given signal. The SVG apparatus then acquired salt conductivity data at $200 \mathrm{~Hz}$. The model described above (Eq. 3) was run at the end of the measurements, and output the fitted values of the flow velocity, which are hereafter denoted "measured velocity".

Each series of measurement at the multiplexed four locations was repeated three times. Measured and modelled peaks, as well as the flow velocity, were displayed on the computer in real time. This procedure allowed operator B to assess the quality of the measurement, and eventually to request another trial of three replications at the same place. Not more than six replications were done, even in the case of repeated unsatisfactory results. Whatever the measurement quality was considered to be in the field, all the measurements were recorded in the computer together with additional details output by the inverse modelling procedure.

This procedure resulted in a total of 348 individual velocity measurements covering 72 different locations. After the experiment, the entire set of recorded data (i.e. disregarding the initial, subjective, quality assessment done in real time on the field) went through a procedure that rejected unreliable results. In this procedure, a high degree of confidence in the data used has been imposed, at the cost of a smaller final dataset. 122 individual measurements, covering 68 locations, have finally been selected by this automatic procedure for further analysis. 
2 The rainfall-simulation site was located at Thies, Senegal (1445'43" N, 1653'16" W). The

3 plot was $10 \mathrm{~m}$ long by $4 \mathrm{~m}$ wide, with a 1\% slope, and a sandy soil (1\% clay, 7\% silt, $43 \%$ fine

4 sand, 49\% coarse sand). The rainfall simulator was as described by Esteves et al. (2000a). It

5 allowed for rainfall at a constant average intensity of $69 \mathrm{~mm} \mathrm{~h}^{-1}$;. In order to limit wind effects,

6 which may cause noticeable variations of rainfall intensity, simulations were carried out at a

7 maximum wind speed of $1 \mathrm{~m} \mathrm{~s}^{-1}$. Six tipping-bucket rain gauges with electronic recording were

8 placed along the plot borders for monitoring the actual rainfall intensity. The flow discharge

9 was collected in a trough and alternately directed, via a 10-cm flexible hose, into two 150-litre

10 cylindrical buckets, one being filled while the other was drained. The volume in the filling

11 bucket was monitored by electronically recording the rise of a float. The resolution of this

12 apparatus was 2.5 litres. The typical flow discharge at steady state was $0.5 \mathrm{l} \mathrm{s}^{-1}$.

\section{Rainfall-simulation experiment}

14 Because the SVG technology did not allow more than four locations to be measured at a time, the entire set of measurements required more than an hour to complete. Two conditions was needed to make the measurements as comparable as possible to each other, disregarding the precise timings of measurements. Condition 1 is a steady-state flow: the velocity measurements must be carried out at steady rainfall, runoff and infiltration rates. This condition was achieved by using a 2 h 15'-long continuous rainfall at constant rainfall intensity (69 $\mathrm{mm} \mathrm{h}^{-1}$ on average). Flow velocity was measured during rainfall, after the flow discharge had stabilized. Condition 2 was a steady flow-pattern: the flow pattern must not vary significantly during the flow velocity measurement. This condition was achieved by applying rainfall on an already 'old' surface. In this purpose, the surface was prepared on day 1 of the experiment as follows. First, a wetting rainfall of $20 \mathrm{~mm}$ was applied and the plot was manually ploughed to a depth of $50 \mathrm{~cm}$. The surface was then raked in order to form a slight $\mathrm{V}$ shape, with $1 \%$ slope longitudinally and 1\% slope towards the median axis of the plot. The purpose of the $\mathrm{V}$ shape was to prevent a rill from forming near to the edge of the plot. Finally a total of six hours of rainfall have been applied on the plot during days one to five. These rains caused the longitudinal slope to change from straight to slightly concave (fig. 1), while continuous sand deposits developed in the concave downstream part.

The experiment detailed in this article was held on day 7. Days 6 and 8 were used to carry out microrelief measurements with an enlarged version of the relief-meter described by Planchon et al. (2001). It consists of a vertical rod with a sensor at the end that detects the soil surface. Stepper motors allow the apparatus to move in small increments in all directions. The horizontal resolution is $2.5 \mathrm{~cm}$ transversally to the plot and $5 \mathrm{~cm}$ longitudinally. The vertical precision is $0.5 \mathrm{~mm}$. With a maximum acquisition rate of 1.6 point s $\mathrm{s}^{-1}$, the 32,000 measured points of the entire plot required a full working day.

38 At the end of the experiment, a series of digital photographs of the plot were taken from a 39 height of 6 metres above ground level. The pictures were combined in a single file and 40 geometrically corrected so that each pixel corresponds to one square millimetre in the field. 
1 The resulting image can be combined with a DEM to produce virtual images of the surface.

2 Fig. 1 shows one of these views with the relief magnified ten times and the colour contrast

3 enhanced. The native soil appears in black (its natural colour is a yellowish light brown). White

4 and reddish colours correspond to various types of sand deposits.

6 Hydraulic formulas used

7 In terms of the flow hydraulics as discussed above, the Reynolds number is defined as:

$8 \quad \mathrm{Re}=4 \mathrm{ur} / \mathrm{v}$

9 where $u$ is average velocity $\left(\mathrm{m} \mathrm{s}^{-1}\right), r$ is hydraulic radius (m) and $v$ is the fluid kinematic

10 viscosity $\left(\mathrm{m}^{2} \mathrm{~s}^{-1}\right)$. This formula is classically used to estimate $R e$ in shallow free surface flows;

11 e.g. Savat (1980), Gilley et al. (1990), Abrahams et al. (1995), Pilotti and Menduni (1997).

12 The Froude number is:

$13 \quad F r=u / \sqrt{g h}$

14 where $u$ is average velocity $\left(\mathrm{m} \mathrm{s}^{-1}\right), g$ is gravitational acceleration $\left(\mathrm{m} \mathrm{s}^{-2}\right)$ and $h$ is flow depth 15 (m).

The models

18 Three distributed erosion models have been used.

19 PSEM 2D, Plot Soil-Erosion Model 2D (Nord and Esteves, 2005; Esteves et al., 2000b), is a soil-erosion model dedicated to small experimental plots, typically of less than $100 \mathrm{~m}^{2}$. Overland flow is described by the depth-averaged two-dimensional unsteady flow equations commonly referred to as the Saint-Venant equations (Zhang and Cundy, 1989). The friction slopes are approximated using the Darcy-Weisbach equation (Eq. 6) derived for uniform steady

24 flow:

$25 S_{f x}=f f \frac{u_{x}{ }^{2}}{8 g h}, S_{f y}=f f \frac{u_{y}{ }^{2}}{8 g h}$

where $S_{f x}$ is the friction slope in the $x$ direction $\left(\mathrm{m} \mathrm{m}^{-1}\right), S_{f y}$ is the friction slope in the $y$ direction $\left(\mathrm{m} \mathrm{m}^{-1}\right)$ and $u_{x}$ and $u_{y}$ are the velocity components in the $x$ and $y$ directions, respectively $\left(\mathrm{m} \mathrm{s}^{-1}\right)$. The Darcy-Weisbach friction factor, $\mathrm{ff}$, may be spatially variable. The second-order explicit scheme of MacCormack (1969) is used for solving the overland-flow equations. Infiltration is computed at each node using a Green-Ampt model (Green and Ampt, 1911).

MAHLERAN (Model for Assessing Hillslope-Landscape Erosion, Runoff And Nutrients;

33 Wainwright et al. (in review)) is a flexible model that can be used for experimental plots as

34 well as small watersheds. The hydrological and hydraulics components of the model are 
1 essentially as described in Parsons et al. (1997), Wainwright et al. (1999) and Wainwright and

2 Parsons (2002). The hydraulics consists of solving the kinematic wave equation in 1D along

3 the flow direction derived from a DEM which depressions have been previously filled using

4 the algorithm from Planchon and Darboux (2001). The kinematic wave simplification uses the

5 continuity equation (eq. 7) together with the Darcy-Weisbach equation (eq. 8) in one

6 dimension, which provides dynamic feedback between flow and roughness in a more realistic

7 way than in typical applications of the kinematic wave (Scoging, 1992).

$8 \frac{\partial h}{\partial t}+u \frac{\partial h}{\partial x}=e_{x}$

9 where $e_{x}$ is rainfall minus infiltration $\left(\mathrm{m} \mathrm{s}^{-1}\right)$ :

$10 u=\sqrt{\frac{8 g h S}{f f}}$

11 where $S$ is the slope in the flow direction $\left(\mathrm{m} \mathrm{m}^{-1}\right)$.

12 The numerical scheme used with this model is the Euler simple backward difference from

13 Scoging (1992). The flow is routed from each cell to one of the four adjacent cells in a finite

14 difference grid using a topographically based algorithm based on the greatest difference in

15 altitude of the cells. Overland flow is generated as Hortonian (infiltration excess) runoff by

16 determining the difference between the rainfall and infiltration rate or as saturation-excess

17 runoff by comparison with a saturated soil-moisture content. Infiltration rate is predicted using

18 the Smith-Parlange model with modifications to allow runon infiltration and temporally

19 variable rainfall (Wainwright and Parsons, 2002).

20 RillGrow2 (Favis-Mortlock, 1998; Favis-Mortlock et al., 2000) is a model dedicated to the 21 numerical simulation of emerging rill patterns. Space is discretized at a very high resolution so 22 that any cell is considered to be entirely inside, or entirely outside a rill. Each cell is eroding 23 independently to each other. Cells lower while eroding. Eroding cells thus attract more water 24 flow, subsequently increasing the erosive power of the rill. Because of its high computational 25 needs, applications of RillGrow2 are limited to experimental plots of a few tens of square 26 metres.

27 RillGrow2 hydraulics consists of calculating a "potential flow velocity" with a Manning-type 28 equation, based on the water depth:

$29 u_{p o t}=w h S_{f}^{n}$,

30 where $u_{\text {pot }}$ is "potential flow velocity" $\left(\mathrm{m} \mathrm{s}^{-1}\right), w$ is an empirical roughness coefficient, $S_{f}$ is the 31 hydraulic gradient $\left(\mathrm{m} \mathrm{m}^{-1}\right)$ and $n=0.5$.

32 The RillGrow2 numerical scheme is unique in soil-erosion modelling: at each time step, the 33 model checks a single cell, chosen at random, and processes it. The check consists of 34 calculating $u_{\text {pot }}$ and determining whether outflow is possible from this cell. If so, an outlet cell 35 is chosen among eight neighbours according to the steepest descent of the free surface. The 
1 required amount of water is then passed from the source cell to the destination cell in order to

2 level the free surface between the two cells. This procedure is then repeated until all cells have

3 been chosen at the particular time step.

\section{Data preparation}

5 A raw DEM was calculated with 5-cm cells. RillGrow2, which is specifically designed to use 6 fine resolution relief data, was the only model able to run the raw DEM. PSEM_2D needed the 7 following operations on the DEM before numerical oscillations could be avoided: i) 8 resampling at $10-\mathrm{cm}$ resolution, ii) smoothing with a Gaussian filter, iii) removing 9 depressions ${ }^{1}$. MAHLERAN required $50-\mathrm{cm}$ cells to be stable. At this resolution the relief was

10 fully convergent and the flow was always in the direction of slope, which makes acceptable the 11 assumptions underlying the resolution of the kinematic wave in $1 \mathrm{D}$ along the slope direction.

\section{Results and discussion}

\section{Field evidence of various flow conditions}

14 Fig. 2 is a detailed view of Fig. 1 seen from downstream. It shows the rill and its left bank. The 15 original photographs of the plot showed subtle variations of browns. They have been enhanced 16 for contrast, levels and colour saturation by image processing. The resulting map (Figs 1 and 2) 17 shows four different surface-feature patterns, which correspond to four different flow 18 conditions.

19 Location A represents a high point with a convex soil surface. No visible flow occurred there. 20 High points have the colour of the native soil. Considering that transportation by water is 21 supposed to remove preferentially the soil organic matter and the finest size fractions, sediment deposits are expected to have lighter colours, while areas with the colour of the native soil are likely to be sediment sources.

In all attempts to measure flow velocity in locations of type A, the coloured brine was found to leave the injection point very gradually, thus forming a long, coloured tail. This fate indicates a vanishingly small flow velocity at the base of the flow, due to strong interaction with the soilgrain roughness, while the top of the water layer could travel along significant distances. Such a fate is typical of laminar flows. However, this result does not imply that no turbulence could agitate the flow, especially because of raindrops which were the main source of water agitation in these locations. As a result, it was often not possible to carry on SVG measurement in locations of type A because of insufficient peak sharpness.

Location B represents the first visible flow. It is characterized by small undulating furrows, $\sim 10 \mathrm{~mm}$ wide and $2 \mathrm{~mm}$ deep. Uneven sand grains could be observed in these tiny channels, slowly creeping downstream until a raindrop hit them and splashed them away.

\footnotetext{
${ }^{1}$ Neither natural depression nor ponds had developed on the plot during the experiment. However, the raw DEM had some small depressions as the consequence of numerical artefacts, especially in the downstream section of the plot, which was very flat.
} 
1 During SVG measurements, the same "long tailed" plumes as in locations of type A were

2 observed, indicating high interaction with flow bed, and low or little turbulence besides the 3 raindrop-related flow agitation.

4 At location C, a well established stream was flowing. The soil surface was covered by a 5 continuous layer of reddish sand that was slowly creeping downstream.

6 During SVG measurements, the tracer left the injection point in a fraction of a second, 7 indicating a sharp vertical velocity profile that did not allow the tracer to 'stick' to the soil 8 surface, as it did in laminar (or at least less turbulent) conditions.

9 Location D was characterized by white sand deposits with crossed wavy features typical to 10 supercritical flow. The white colour of the sand indicates that the sand grains have been 11 transported by turbulent flow until all clay and organic particles had detached from the grain itself. These field observations indicate that the flow was certainly turbulent and supercritical there. Measured velocities were all above $0.15 \mathrm{~m} . \mathrm{s}^{-1}$. Table 1 summarizes the qualitative information detailed above.

\section{Qualitative results from the models}

Since all infiltration models are known to reproduce well the simple conditions of the experiment with regard to rainfall and infiltration, and the purpose of the study is to investigate the reproduction of hydraulics characteristics, each model was calibrated from the hydrograph in order to remove any variability in the results due to misrepresentation of the infiltration parameters. SVG measurements were not used during calibration. The infiltration parameters were calibrated from the total runoff and the steady infiltration rate. The friction factor was calibrated from the hydrograph rise.

The velocity field from PSEM_2D (fig. 3) is consistent with visual observations. One can notice for example the location of the predicted maximum velocity. It corresponds to the white sands at the centre of the plot, which we interpreted as a mark of supercritical flow. The pattern produced by MAHLERAN is similar to PSEM, with a noticeable loss of precision due to the coarser grid resolution. RillGrow2 predicts a wide area of high velocity in the bottom part of the plot which corresponds fairly well to the concave area of reddish sand deposits that can be seen in figures 1 and 3.

The Re predictions follow approximately the same pattern as the flow velocity. However, according to the threshold of 2000 commonly used for the transition between laminar and turbulent flows, the spatial extension of turbulent flow is underestimated with regard to the results of visual observations reported in the previous section. $\mathrm{Fr}$ is even more problematic since no pattern at all is predicted by PSEM_2D or NCF while the pattern predicted by RillGrow2 is not consistent with the field evidence reported above. 
1 Comparison of measured and modelled velocity

2 Fig. 4 shows the modelled velocity compared to the observed ones. All models have a better fit

3 at low velocities than at higher ones. PSEM_2D and MAHLERAN slightly overestimate the

4 low velocity and strongly underestimate the high ones. RillGrow2 simulates very well the

5 slowest flows (i.e. $\mathrm{u}<0.05 \mathrm{~m} \mathrm{~s}^{-1}$ ) and underestimates the other cases. Precisely localized

6 maxima or minima cannot be expected to be reproduced by MAHLERAN since measured

7 velocities are averaged over $10 \mathrm{~cm}^{2}$ while the model results represent a $0.25 \mathrm{~m}^{2}$ cell. However, 8 underestimation of velocity values higher than $0.1 \mathrm{~m} \mathrm{~s}^{-1}$ is a common result to all models.

9 Moreover, the degree of underestimation is similar in all of the models, despite the fact that

10 their cell sizes differ largely. The working hypothesis for further analysis in this article will

11 therefore be that the underestimation of velocities higher than $0.1 \mathrm{~m} \mathrm{~s}^{-1}$ has a common cause

12 that is shared by the three models.

\section{Modelling the interaction between friction factor and flow conditions}

15 Underestimation of flow velocity can be solved by using lower values of $f f$ at the 16 corresponding locations. PSEM_2D allows for spatially non-uniform values of $\mathrm{ff}$ at a high 17 resolution; it is working at a finer scale and solves the full St Venant equations hence not 18 limited by the assumptions of the other models. It has therefore been chosen as the best 19 candidate for validating this approach. The following steps were followed.

20 The first step was to fit the velocity modelled by PSEM_2D (Fig. 4) to Eq. 10, which describes 21 empirically the gradually increasing underestimation of modelled velocity.

where $a=0.5 ; b=0.28 ; u_{0}$ is measured velocity and $u_{1}$ is the velocity predicted by PSEM_2D.

The second step was to consider the set of equations 10 to 13 for estimating the corrected value of $f f$, hereafter denoted $f f_{1}$, that will solve the bias described by Eq. 10. Eq. 11 states the unit discharge at a given location will not change after $f f$ is corrected from $f f_{0}$ to $f f_{1}$ :

$29 u_{0} \cdot h_{0}=u_{1} \cdot h_{1}$

30 The Darcy-Weisbach equation before and after correction, are, respectively:

$31 \quad u_{0}=\sqrt{\frac{8 g h_{0} s}{f f_{0}}}$

$32 \quad u_{1}=\sqrt{\frac{8 g h_{1} s}{f f_{1}}}$

33 The solution to this set of equations is thus: 
$1 \quad f f_{1}=f f_{0} \cdot u_{0}\left(3-\frac{3}{a}\right) \cdot b^{\left(\frac{3}{a}\right)}$

2 where $f f_{0}=0.26$, the initial calibrated uniform value of $f f$ used in the model; $h_{0}$ and $u_{0}$ are flow 3 depth and flow velocity read at a given cell in the PSEM_2D results shown in fig. 3 and 4; $u_{1}$ is

4 the observed velocity; and $h_{1}$ is the corresponding flow depth according to the modelled unit 5 discharge.

$6 \quad f f_{1}$ was calculated from Eq. 14 at each cell. The resulting map was then smoothed to prevent the 7 model from generating instabilities. A threshold of $f f<2$ was finally applied to account for 8 inconsistent velocities predicted at very small water depths, although the value of this threshold 9 proved to have little influence on the final result.

10 Fig. 5 shows the resulting maps for $u, R e$ and $F r$. The $F r>1$ limit is in fair agreement with the limits of the white sands that has been interpreted as the mark of supercritical flow. The $R e>2000$ limit is wider than in the previous simulation (albeit still limited to the central channel). Fig. 6 shows the graph of modelled vs observed velocity. Results are scattered around the 1:1 line, which is the expected result of the use of Eq. 14. Figures 5 and 6 show that the results with varying $f f_{1}$ are far more realistic, and closer to the field observations, than those obtained from homogeneous $\mathrm{ff}$. Independent data are however lacking to assess the exact meaning of ff calculated this way, which will therefore be denoted "apparent ff" hereafter. The physical significance of apparent $f f$ values calculated individually for 10 -cm cells is also an issue because of inherent scale-dependence in the derivation of roughness coefficients (Müller, 2004).

It is worth mentioning that the change from calibrated uniform $f f$ to calibrated non uniform $\mathrm{ff}$ has not changed the hydrograph, despite this change has led to almost doubling the value of the highest simulated velocity. This lack of sensitivity of the hydrograph to the high velocity values is probably very common.

Similarly to any natural watershed, the plot was divided into two areas: a "slow" one at the border, denoted S, which covered $91 \%$ of the plot area, and a "fast" one at the centre, denoted $\mathrm{F}$, and covering $9 \%$ of the plot. Because virtually all water flowing on the plot eventually concentrates in $\mathrm{F}$, there is intuitive evidence that the hydrograph is sensitive to any change in the flow velocity in F, disregarding its little importance in terms of area. This reasoning has led to the widely accepted idea (especially in soil erosion modelling) that flow velocity in F can be calibrated from the hydrograph. Our experiment has shown that this procedure can produce unreliable results in many cases.

On the plot, $\mathrm{F}$ can be defined as the area where $u>0.1 \mathrm{~m} \mathrm{~s}^{-1}$. The average fate of a raindrop falling at the surface of the plot and flowing downstream has been calculated from the flowvelocity field output by PSEM_2D. This imaginary raindrop spent $t_{s+f}=66 \mathrm{~s}$ on the plot, divided in $t_{s}=41 \mathrm{~s}$ spent in $\mathrm{S}$ and $\mathrm{t}_{\mathrm{f}}=25 \mathrm{~s}$ spent in $\mathrm{F}$. As a result of the longer time spent at 
low speed, a change of $1 \%$ in the flow velocity in $\mathrm{S}$ results in a change of $0.62 \%$ in $\mathrm{t}_{\mathrm{s}+\mathrm{f}}$ while the same change in $\mathrm{F}$ results only in a $0.38 \%$ change in $t_{\mathrm{s}+\mathrm{f}}$. Velocity faster than $0.1 \mathrm{~m} \mathrm{~s}^{-1}$, which are of crucial importance to soil erosion, had even less influence on the hydrograph: the same $1 \%$ change in velocity values higher than 0.15 and $0.2 \mathrm{~m} \mathrm{~s}^{-1}$ produced, respectively, a change of $0.28 \%$ and $0.08 \%$ in the average time to the outlet.

In brief, using calibrated values of $\mathrm{ff}$ in a soil-erosion model is likely to provide the most reliable velocity values at low speed, where no erosion occurs, at the cost of potentially large errors on the flow velocity at the eroding places.

\section{ff-Re relationship}

Fig. 7 shows a log-log plot of the relationship between apparent $f f$ and $R e$. It shows that apparent ff was high at low Reynolds numbers and decreased with increasing $R e$. This relationship is consistent with observations from Nearing et al. (1997) as well as Dunkerley et al. (2001), which fall in the case of no backward interaction of flow conditions to the bed roughness and roughness elements are small with regard to flow depth, both conditions being the case in our experiment. Fig. 8 compares our results to those from Nearing et al. (1997). Each line was drawn within the data limits of the corresponding experiment. It appears that our results are in continuity to those from Nearing et al. (1997). However, in our experiment, the dependency of $f f$ on $R e$ is weaker than in the study from Nearing et al. (1997). It is likely that the calibrated, apparent $f f$ incorporates more than the strict relationship of the flow to the soil roughness. In particular, some scale effect linked to the cell size must be expected. Additional experiments in various conditions of flow and slope would probably allow a better understanding of the reasons of the differences between the two studies.

\section{Onset of rilling}

In this work, we have calculated apparent ff values in order to allow PSEM_2D to reproduce the flow velocity at the 68 measured locations. The resulting modelled velocity field was found to be consistent with field evidences of supercritical flow within the central channel, and reasonably consistent with field evidence of turbulent flow in all channels, i.e. the central one and its principal tributaries. The field evidence gives a high degree of confidence to the simulated values of flow velocity as well as the corresponding flow depth.

The result supports the hypothesis based on Gimenez et al. (2004) experiment, as discussed in the introduction. According to this hypothesis, a supercritical flow velocity is a necessary condition for rills to start. The key point is that supercritical flow allows the formation of small hydraulic jumps where the development of strong turbulence triggers the erosion of what will be the rill head. Fr could therefore be a good candidate to use in models in order to predict the location and timing of rill onset, and therefore to better predict whether a given storm will 
1 Our results have also shown that a satisfactory simulation of $\mathrm{Fr}$ must take into account the 2 interaction between Re and apparent ff. While the observed relationship is consistent with the 3 literature, this relationship is known to exhibit considerable variations with flow conditions, as 4 well as with the nature and size of roughness elements. More research is needed to investigate this relationship in more complex situations than the raked, planar, smooth sandy surface used in this experiment, where grain roughness was dominating the interactions between the flow and the soil surface.

\section{Conclusion}

The SVG technology has allowed flow-velocity measurement in a wide range of flow speeds (from $0.006 \mathrm{~m} . \mathrm{s}^{-1}$ to $0.27 \mathrm{~m} . \mathrm{s}^{-1}$ in this experiment). The use of salty brine as a tracer makes SVG suitable for measuring very shallow flows. The only limitation was the probe size, which was $1-\mathrm{cm}$ wide and $10-\mathrm{cm}$ long. Thanks to this technology, we were able to measure velocity in a wide variety of flow conditions, from unconcentrated to concentrated in a small rill, from laminar to turbulent, and from subcritical to supercritical. The data obtained have been used to test three hydrological models (PSEM_2D, MAHLERAN, and RillGrow2) which were very different from each other, having only in common the use of a Manning/Darcy-Weisbach-type hydraulic equation with a constant, homogeneous friction factor. The main results were the following:

- PSEM_2D, MAHLERAN and RillGrow2 to a lesser extent, simulated satisfactorily the patterns of flow velocity and Reynolds number $R e$.

- The Froude number $\mathrm{Fr}$ was not predicted by any of the three models. Even the general pattern was missed.

- Low velocities were overestimated (PSEM_2D and MAHLERAN). High velocities were largely underestimated (all models).

- Re values estimated by the models are realistic. However, the classical threshold of $R e=2000$ for the transition between laminar to turbulent flow, would predict laminar flow everywhere on the plot but in the central channel, while field observations suggested the presence of turbulence even in the tributaries of the main channel.

- An apparent friction factor $f f$ was calculated at each cell in order to fit the modelled velocity with the whole range of observed values. Running PSEM_2D with the apparent $f f$ has improved the simulation of $\mathrm{Re}$ and $\mathrm{Fr}$ patterns. Moreover, apparent $f f$ appeared to be related to $R e$ via a power law similar to the one observed by Nearing et al. (1997) on sandy bare soil (albeit the range of $f f$ and $R e$ differed in the two studies).

These results lead to the following conclusions:

- The hydrograph alone is an insufficient source of information to calibrate ff (see also Parsons et al., 1994). Other sources of data such as the measured velocity field are therefore 
highly desirable to calibrate any hydrological model dedicated to be coupled to an erosion model.

- ff decreases with increasing Re, which we interpreted by the fact that the flow becomes less sensitive to soil roughness when its turbulence increases. This result supports the conclusion of Nearing et al. (1997) for sandy bare soils and extends them to lower values of $R e$ than in their study.

- The usual procedure in soil-erosion models is the calibration, from the hydrograph, of a single value of $\mathrm{ff}$ for the whole plot. Our results show that this procedure will correctly calibrate the friction factor at cells where velocity is low to moderate, which dominate the hydrological response of the plot. Contrarily, the hydrograph will not be significantly affected by an even dramatic underestimation of the highest velocity because the corresponding error in terms of average travel time will be small.

- Uniform $\mathrm{ff}$ leads to erroneous patterns of Fr. However, when measured velocities are used to calibrate non-uniform values of $f f, F r$ patterns and values are satisfactory. Gimenez et al. (2004) have demonstrated the importance of Fr in the development of rills. Any future model aimed at simulating rill initiation on the basis of these findings should account for the ff-Re relationship in order to have realistic simulations of $\mathrm{Fr}$ for using at predicting rill initiation.

- The results support the hypothesis according to which supercritical flow is a necessary condition to the onset of rilling.

\section{Acknowledgements}

24 This work was granted by the RIDES project, an ECCO research program. The experiment was hosted by the Ecole Nationale Supérieure d'Agriculture (ENSA) of Thies, Senegal. The new miniaturized version of SVG has been developed in a collaborative project between the Institut de Recherche pour le Développement (IRD) and the USDA-ARS National Soil Erosion Laboratory (NSERL). The authors are very thankful to Kokou Abotsi, from IRD Dakar,

29 Senegal, who has been in charge of the construction, operation and maintenance of the rainfall

30 simulations facility. 


\section{References}

Abrahams, A.D., Parsons, A.J., Wainwright, J., 1995. Effects of vegetation change on interrill runoff and erosion, Walnut-Gulch, Southern Arizona. Geomorphology, 13, 37-48.

Abrahams, A.D., Li, G. and Parsons, A.J., 1996. Rill hydraulics on a semiarid hillslope, Southern Arizona. Earth Surface Processes and Landforms, 21, 35-47.

Cerdan, O., Le Bissonnais, Y., Couturier, A., Bourennane H., Souchere V., 2002. Rill erosion on cultivated hillslopes during two extreme rainfall events in Normandy, France. Soil and Tillage Research, 67(1), 99-108.

Chaplot, V., Giboire, G., Marchand, P., Valentin C., 2005. Dynamic modelling for linear erosion initiation and development under climate and land-use changes in northern Laos. Catena, 63 (2-3 Special Issues), 318-328.

Darboux, F., Huang, C., 2005. Interactions between overland flow and soil surface roughness. Does soil surface roughness increase or decrease water and particle transfers? Soil Science Society of America Journal, 69(3), 748-756.

Desmet, P.J.J., Govers, G., 1997. Two-dimensional modelling of the within-field variation in rill and gully geometry and location related to topography. Catena, 29, 283-306.

Desmet P.J.J., Poesen, J., Govers, G., Vandaele, K., 1999. Importance of slope gradient and contributing area for optimal prediction of the initiation and trajectory of ephemeral gullies. Catena, 37, 377-392.

Dunkerley, D., Domelow, P., Tooth, D., 2001. Frictional retardation of laminar flow by plant litter and surface stones on dryland surfaces: A laboratory study. Water Resources Research, 37(5), 1417-1423.

Esteves, M., Planchon, O., Lapetite, J.M., Silvera, N., Cadet, P., 2000a. The 'EMIRE' large rainfall simulator: Design and field testing. Earth Surface Processes and Landforms, 25, 681-690.

Esteves, M., Faucher, X., Galle, S., Vauclin, M., 2000b. Overland flow and infiltration modelling for small plots during unsteady rain: numerical results versus observed values. Journal of Hydrology, 228, 265-282.

Favis-Mortlock, D., 1998. A self-organizing dynamic systems approach to the simulation of rill initiation and development on hillslopes. Computers \& Geosciences, 24(4), 353-372.

Favis-Mortlock, D.T., Boardman, J., Parsons, A.J. and Lascelles, B., 2000. Emergence and erosion: a model for rill initiation and development. Hydrological Processes, 14, 21732205.

Gilley, J. E., Lane, L.J., Laflen, J.M., Nicks, H.D., Rawls, W.J., 1988. USDA-water erosion prediction project: New generation erosion prediction technology. In: Modelling Agricultural, Forest, and Rangeland Hydrology. Symposium Proceedings. Pub. 07-88:260-263. Available from Am. Soc. Agric. Eng., St. Joseph, MI.

Gilley, J.E., Kottwitz, E.R., Simanton, J.R., 1990. Hydraulic characteristics of rills. Trans. Am. Soc. Agric. Eng., 33, 1900-1906.

Gimenez, R., Govers, G., 2001. Interaction between roughness and flow hydraulics in eroding rills. Water Resources Research, 37, 791-799. 
Gimenez, R., Planchon, O., Silvera, N., Govers, G., 2004. Longitudinal velocity patterns and bed morphology interaction in a rill. Earth Surface Processes and Landforms, 29, 105-114.

Gómez J. A., Darboux F., Nearing M.A., 2003. Development and evolution of rill networks under simulated rainfall. Water Resources Research, 39(6), 1148. doi: 10.1029/2002WR001437

Govers, G., 1992. Relationship between discharge, velocity and flow area for rills eroding loose, nonlayered materials. Earth Surface Processes and Landforms, 17, 515-528.

Grant, G.E., 1997. Critical flow constrains flow hydraulics in mobile-bed streams: A new hypothesis. Water Resources Research, 33, 349-358.

Green, W. H., Ampt, G. A. 1911. Studies on soil physics: 1, flow of air and water through soils. Journal Agric. Sciences, 4, 1-24.

Hayami S. 1951. On the Propagation of Flood Waves. Disaster Prevention Research Institute, Kyoto University, Japan, Bulletin no. 1.

Henderson, FM., 1966. Open Channel Flow. New York: Macmillan Company.

Hessel, R., Jetten, V., Guanghui, Z. 2003. Estimating Manning's n for steep slopes. Catena, 54, 77-91.

Järvelä, J., 2002. Flow resistance of flexible and stiff vegetation: a flume study with natural plants. Journal of Hydrology 269(1-2), 44-54.

Jetten, V., de Roo, A., Favis-Mortlock, D., 1999. Evaluation of field-scale and catchment-scale soil erosion models. Catena, 37(3-4), 521-541.

Jetten, V., Govers, G., Hessel, R., 2003. Erosion models: quality of spatial predictions. Hydrological Processes. 17, 887-900.

MacCormack, R.W., 1969. The effect of viscosity in hypervelocity impact cratering. American Institute of Aeronautics and Astronautics. Paper 69-354, New-York.

Mancilla, G.A.; Chen, S., McCool, D.K., 2005. Rill density prediction and flow velocity distributions on agricultural areas in the Pacific Northwest. Soil \& Tillage Research, 84(1), 54-66.

Montgomery, D.R., Dietrich, W.E., 1992. Channels initiation and the problem of landscape scale. Science, 255, 826-830.

Müller, E.N., 2004. Scaling approaches to the modelling of water, sediment and nutrient fluxes within semi-arid landscapes, Jornada Basin, New Mexico. Unpublished PhD thesis, King's College London, UK.

Nearing, M.A., Norton, L.D., Bulgakov, D.A., Larionov, G.A., West, L.T., Dontsova, K.M., 1997. Hydraulics and erosion in eroding rills. Water Resources Research, 33, 865-876.

Nord, G., Esteves, M., 2005. PSEM_2D: a physically-based model of erosion processes at the plot scale. Water Resources Research. 41(8): Art. No. W08407.

Parsons, A.J. 1987. The role of slope and sediment characteristics in the initiation and development of rills. In Godard A and Rapp A. (eds) Processus et mesure de l'erosion, 211-220, Editions du CNRS, Paris.

Parsons, A.J., Abrahams, A.D. and Wainwright, J. 1994. On determining resistance to interrill overland flow. Water Resources Research, 30, 3515-3521.

Parsons, A.J., Wainwright, J., Abrahams, A.D., Simanton, J.R., 1997. Distributed dynamic modelling of interrill overland flow. Hydrological Processes, 11(14), 1833-1859. 
Patton P.C., Schumm S.A., 1975. Gully erosion, Northwest Colorado: a threshold phenomenon. Geology, 3, 83-90.

Pilotti, M., Menduni, G., 1997. Application of lattice gas techniques to the study of sediment erosion and transport caused by laminar sheetflow. Earth Surface Processes and Landforms, 22, 885-893.

Planchon, O., Darboux, F., 2001. A fast, simple and versatile algorithm to fill the depressions of digital elevation models. Catena, 46(2-3), 159-176.

Planchon, O., Esteves, M., Silvera, N., Lapetite, J.M., 2001. Microrelief induced by tillage: measurement and modelling of Surface Storage Capacity. Catena, 46(2-3), 141-157.

Planchon, O., Silvera, N., Gimenez, R., Favis-Mortlock, D., Wainwright, J., Lebissonnais, Y., Govers, G., 2005. Estimation of flow velocity in a rill using an automated salt-tracing gauge. Earth Surface Processes and Landforms, 30, 833-844.

Rieke-Zap, D. H., Nearing M.A., 2005. Slope Shape Effects on Erosion: A Laboratory Study. Soil Sciences Society of America Journal, 69(5), 1463-1471.

Roo, A.P.J. de, Wesseling, C.G., Ritsema, C.J., 1996. LISEM: a single event physically-based hydrologic and soil erosion model for drainage basins: I Theory, input and output. Hydrological Processes, 10(8), 1107-1117.

Savat, J., 1980. Resistance to flow in rough supercritical sheet flow. Earth Surface Processes and Landform, 5: 103-122.

Scoging, H., 1992. Modelling overland-flow hydrology for dynamic hydraulics. In: A. J. Parsons, A. D. Abrahams (Eds), Overland Flow Hydraulics and Erosion Mechanics.. London, UCL Press, 89-103.

Song, W., Liu, P.L., Yang, M.Y., Xue, Y.Z., 2003. Using REE tracers to measure sheet erosion changing to rill erosion. Journal of Rare Earths, 21(5), 587-590.

Thorne, C.R., Zevenbergen, L.W., 1990. Prediction of ephemeral gully erosion on cropland in the Southeastern. United States. In: J. Boardman, I.D.L. Foster, J.A. Dearing, Editors, Soil Erosion on Agricultural Land, Wiley, Chichester (1990): 447-460.

Vandaele, K., Poesen, J., Marques da Silva, J.R., Desmet, P., 1996. Rates and predictability of ephemeral gully erosion in two contrasting environments. Geomorphology, Relief, Processes and Environment, 2, 83-96.

Wainwright, J., Parsons, A.J., Abrahams, A.D., 1999. Field and computer simulation experiments on the formation of desert pavement. Earth Surface Processes and Landforms, 24, 1025-1037.

Wainwright, J., Parsons, A.J., 2002. The effect of temporal variations in rainfall on scale dependency in runoff coefficients. Water Resources Research, 38(12), 1271. Doi: 10.1029/2000WR000188.

Wainwright, J., Parsons, A.J., Müller, E.N., Brazier, R.E., Powell, D.M., Fenti, B., in review. A transport-distance approach to scaling erosion rates: model development and testing. Earth Surface Processes and Landforms.

Whiting, P.J.; Bonniwell, E.C.; Matisoff, G., 2001. Depth and areal extent of sheet and rill erosion based on radionuclides in soils and suspended sediment. Geology, 29(12), 11311134. 
1 Yang, M.Y.; Walling, D.E.; Tian, J.L.; Liu, P.L., 2006. Partitioning the contributions of sheet 2 and rill erosion using beryllium-7 and cesium-137. Soil Science Society of America Journal, 3 70(5), 1579-1590

4 Zhang, W., Cundy, T. W., 1989. Modelling of two dimensional overland flows. Water $5 \quad$ Resources Research, 25, 2019-2035. 
List of captions:

Figure 1. Location of the velocity measurements showed on a virtual picture of the plot. Vertical axis has been magnified ten times. Colour contrast has been enhanced. The native soil appears in black. White and reddish colours correspond to various types of sand deposits (see text for details).

Figure 2. Detail of the left bank of the rill viewed from downstream. Light blue crosses show velocity measurement locations. Coloured arrows are modelled flow velocity. Capital letters show the four surface features that develop on the plot (see comments in text). Axis labels are in $\mathrm{mm}$.

Figure 3. Picture of the plot (with contrast magnified) compared to the velocity, Re and Fr maps predicted by the three models. Calibrations based on the hydrograph.

Figure 4. Modelled velocity against measured values for the three models.

Figure 5. PSEM_2D results with ff calculated from Eq. 14: output maps compared with the picture of the plot.

Figure 6. PSEM_2D modelled velocity with ff calculated from Eq. 14.

Figure 7. Relationship between friction factor $f f$ and Reynolds number Re simulated by PSEM_2D with friction factor calculated from Eq. 14.

Figure 8. Relationship between Friction factor $f f$ and Reynolds number Re: comparison with results from Nearing et al. (1997).

Table 1. Qualitative information on flow conditions deduced from field observation during rainfall, and from surface-feature description after the experiment. 


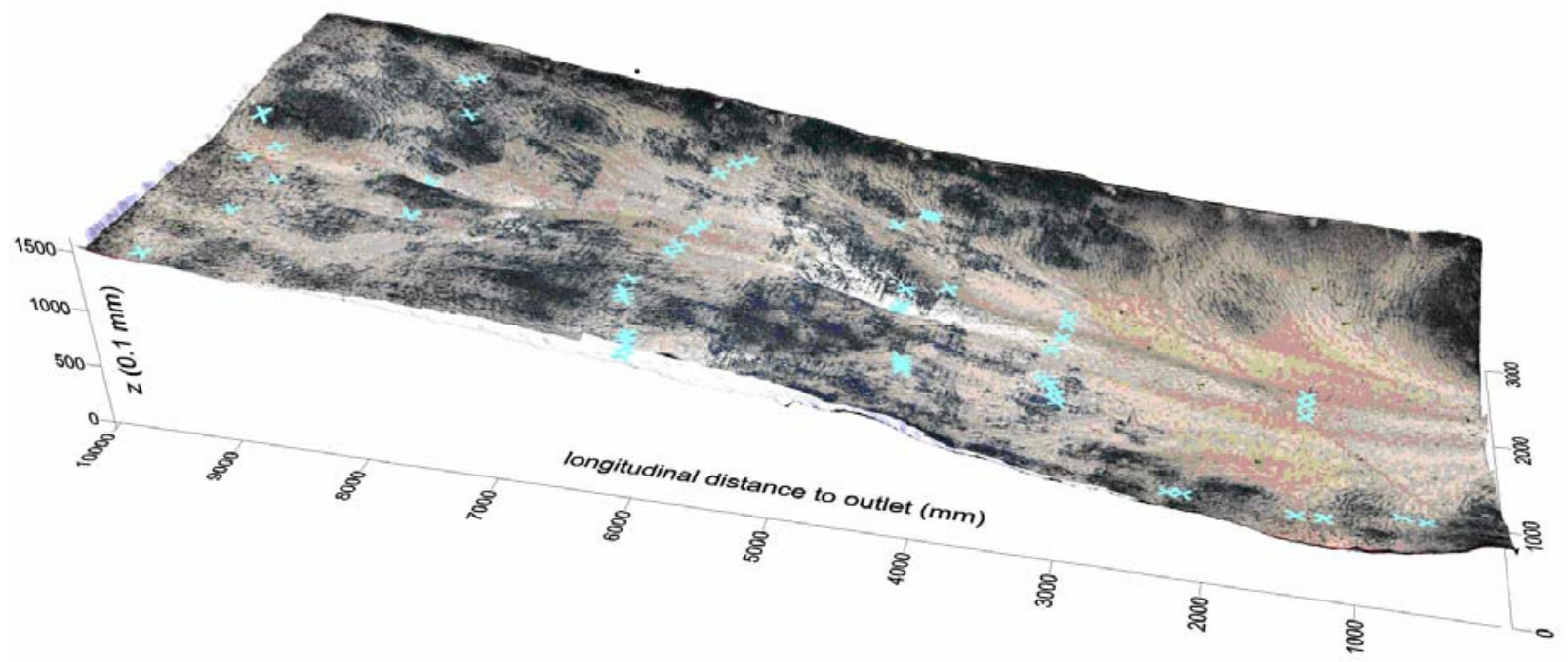

1

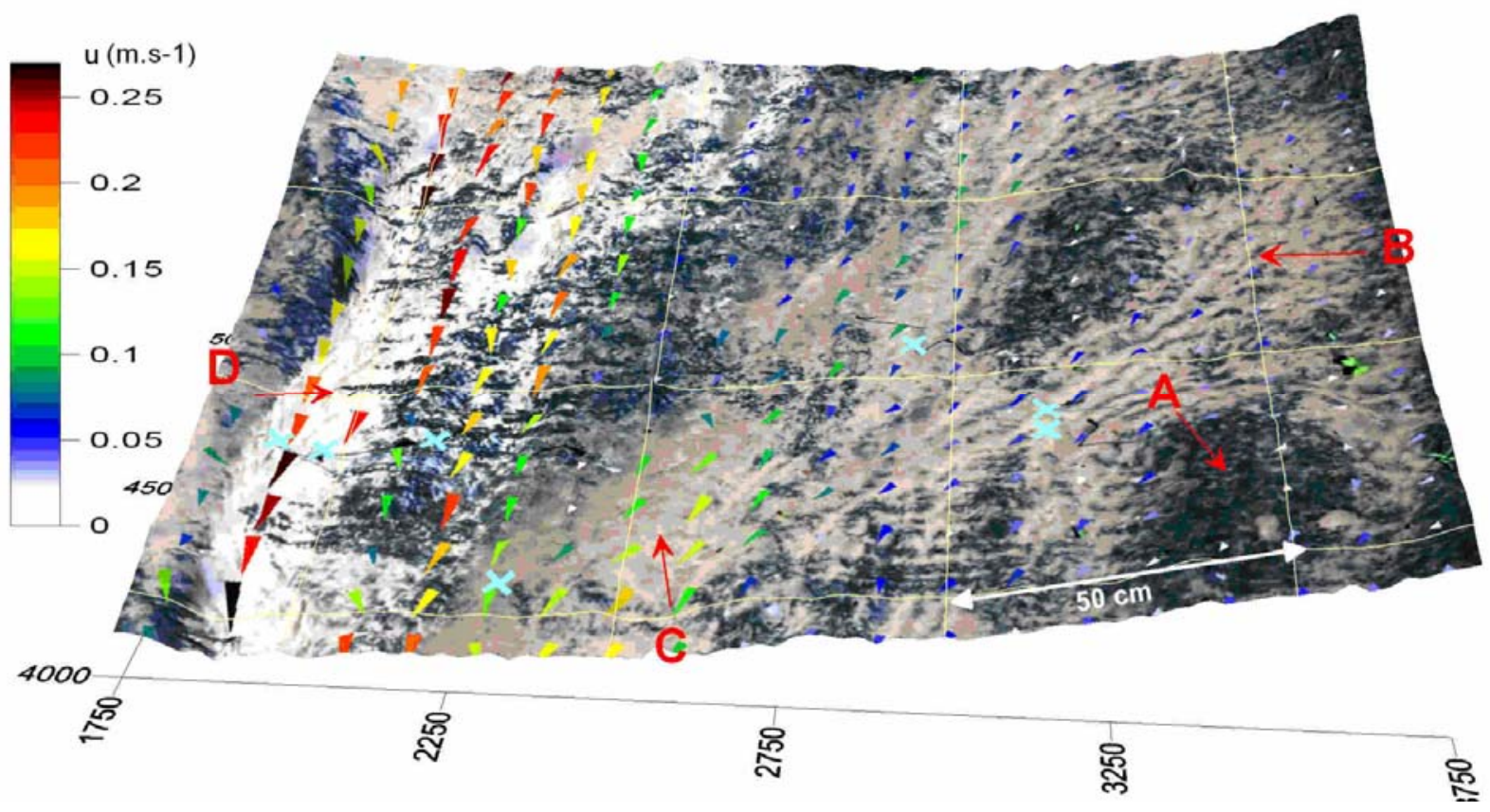



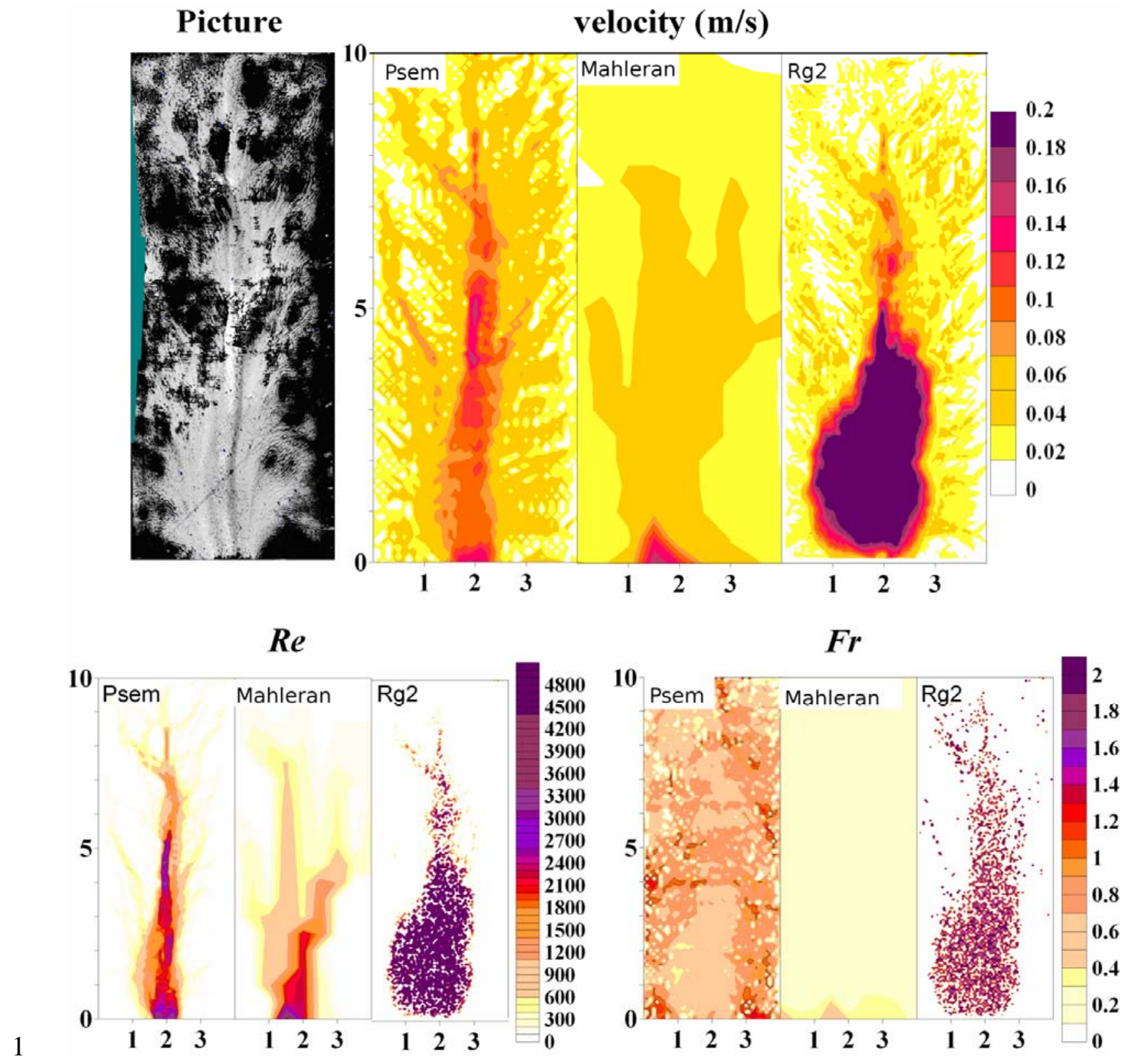


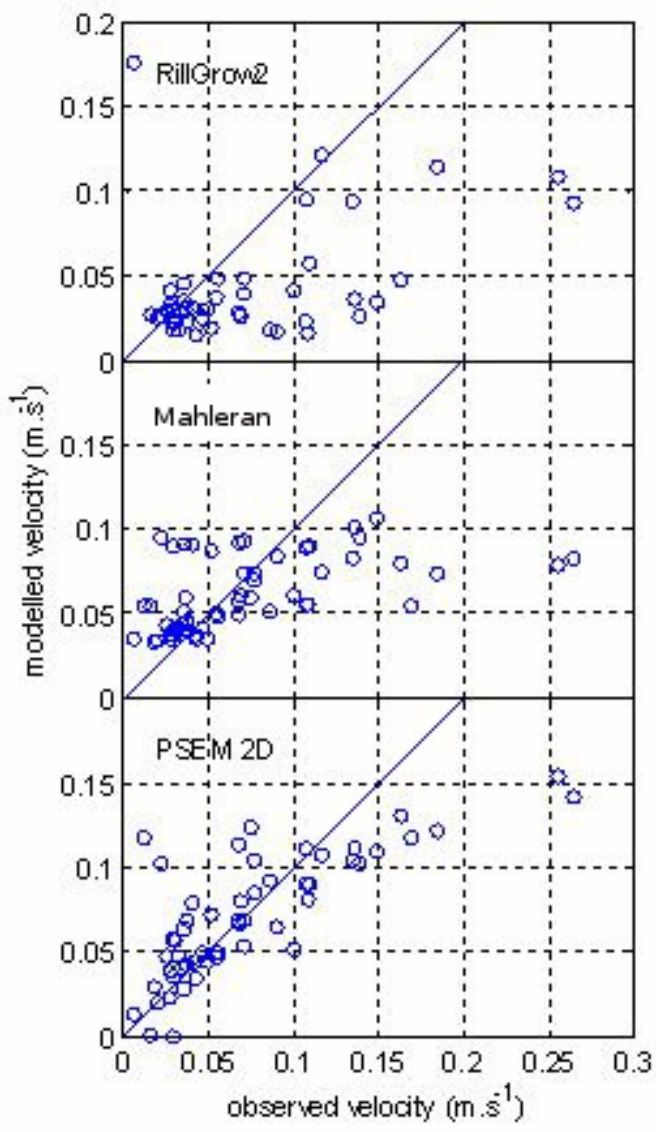

1 

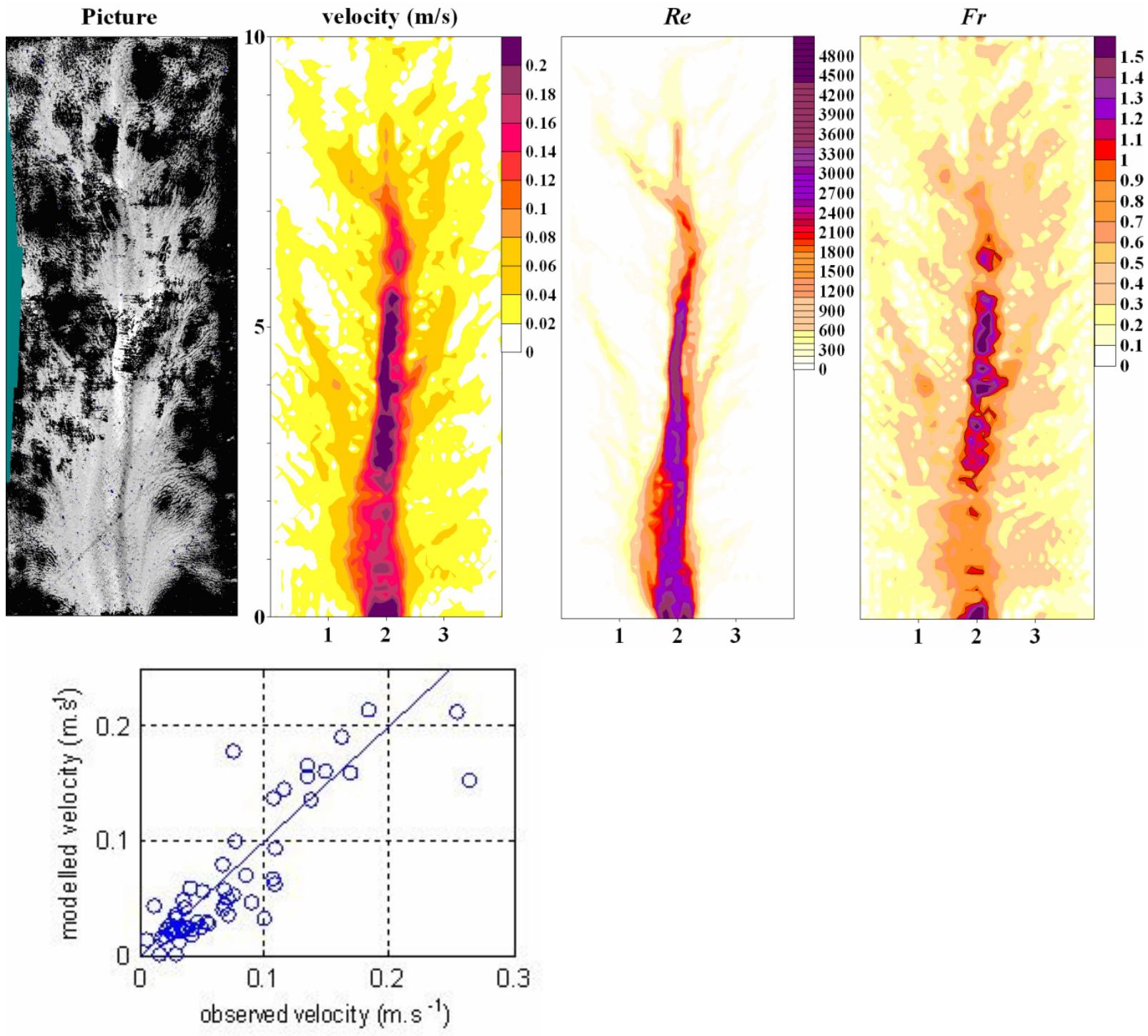


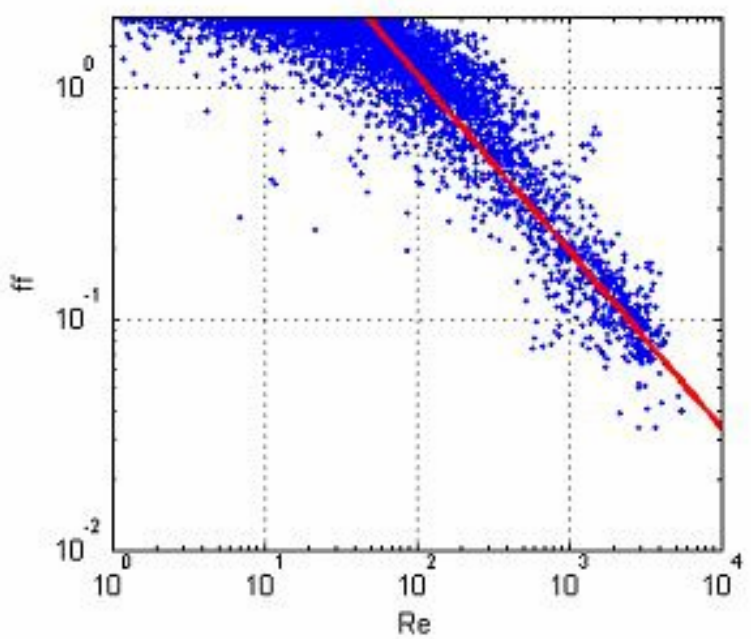

1

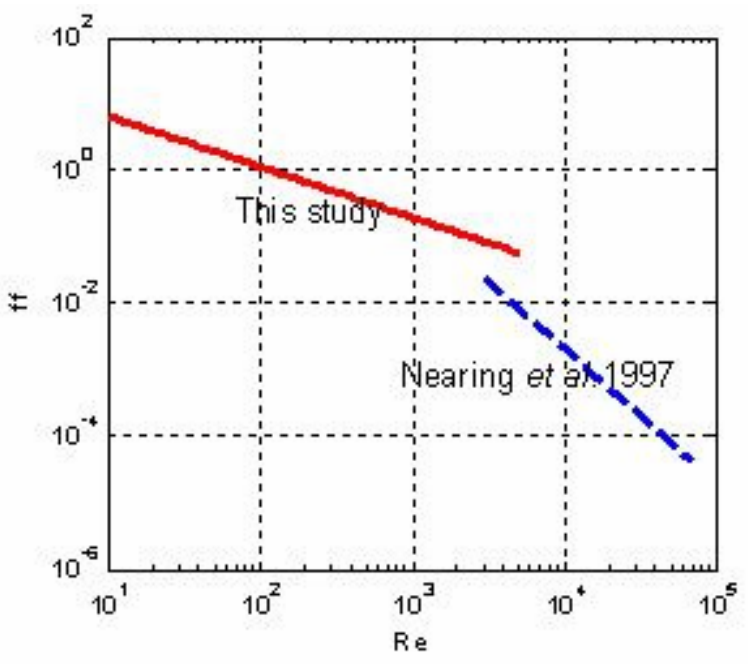




\begin{tabular}{|c|c|c|c|}
\hline Location & $\begin{array}{c}\text { Surface } \\
\text { feature from } \\
\text { observation }\end{array}$ & Turbulence & Flow regime \\
\hline$A$ & $\begin{array}{l}\text { Native soil, } \\
\text { light brown }\end{array}$ & \multirow{2}{*}{$\begin{array}{l}\text { Laminar, agitated by } \\
\text { raindrop impacts }\end{array}$} & \multirow{3}{*}{ Subcritical } \\
\hline B & $\begin{array}{c}\text { Discontinuous } \\
\text { sand deposit }\end{array}$ & & \\
\hline$C$ & $\begin{array}{c}\text { Continuous } \\
\text { reddish sand } \\
\text { deposit }\end{array}$ & \multirow[b]{2}{*}{ Turbulent } & \\
\hline D & $\begin{array}{c}\text { Continuous } \\
\text { white sand } \\
\text { deposit with } \\
\text { crossed wavy } \\
\text { features }\end{array}$ & & Supercritical \\
\hline
\end{tabular}

2

3 Table 1

4

5

6 